\title{
Correction to: How do Mandarin speakers conceptualize time? Beyond the horizontal and vertical dimensions
}

\author{
Juan Sun ${ }^{1}$ (1) $\cdot$ Qiang Zhang ${ }^{2}$
}

Published online: 28 May 2021

(c) Marta Olivetti Belardinelli and Springer-Verlag GmbH Germany, part of Springer Nature 2021

\section{Correction to: Cognitive Processing \\ https://doi.org/10.1007/s10339-020-00987-3}

In the original publication of the article, the following term was incorrectly published as "mainland China"; however, the correct term should read as "Chinese mainland."

This has been corrected in this paper.

Publisher's Note Springer Nature remains neutral with regard to jurisdictional claims in published maps and institutional affiliations.

The original article can be found online at https://doi.org/10.1007/ s10339-020-00987-3.

Juan Sun

sunjuan5@mail.sysu.edu.cn; sjhsunjuan2008@hotmail.com

1 School of Foreign Languages, Sun Yat-sen University, No.135, Xingang Xi Road, Guangzhou 510275, China

2 School of Foreign Languages, Shandong University, No.5 Hongjialou Road, Jinan 250100, China 